\title{
La concesión de la ciudadanía romana por el emperador
como acto de evergetismo romana por el emperador
como acto de evergetismo
}

Pedro López Barja de Quiroga

Universidade de Santiago de Compostela, España pedro.barjadequiroga@usc.es

Recibido: 21/03/2020. Aceptado: 14/04/2020.

\begin{abstract}
Resumen
La concesión de la ciudadanía romana por el emperador tenía que responder a estrictos criterios de justicia, para evitar ser considerada un acto arbitrario y por lo tanto tiránico. En este caso, la justicia dictaba que el fin de este favor imperial sólo podía ser el de incrementar el número de ciudadanos, lo que en sí mismo era un acto de evergetismo, pues proporcionaba un sólido fundamento a la res publica.
\end{abstract}

Palabras clave: Plinio el Joven, Trajano, constitutio Antonina, ius Latii, beneficium.

\section{The Imperial Grants of Roman Citizenship as an Act of Evergetism}

\begin{abstract}
The granting of Roman citizenship by the emperor had to meet strict criteria of justice, in order to avoid being considered an arbitrary act, and therefore tyrannical. In this case, justice dictated that the end of this imperial favor could only be to increase the number of citizens, which in itself was an act of evergetism, since it provided a solid foundation for the res publica.
\end{abstract}

Keywords: Pliny the Younger, Trajan, constitutio Antonina, ius Latii, beneficium.

Había muy diversas ciudadanías en el Imperio romano, si bien no todas, naturalmente, estaban en el mismo nivel y, por esta razón, es importante calibrar las consecuencias que tenía para una persona determinada el cambiar de una ciudadanía a otra. Aunque no podemos dar una cifra concreta (volveremos sobre este punto enseguida), todos los años, en diversas partes del Imperio, eran muchos los que pasaban de una ciudadanía local a la romana, con las complicaciones que esto suponía. En el otro extremo 
de esta relación bilateral se encontraba el emperador. De los numerosos beneficia de los que podía disponer libremente, la ciudadanía romana figuraba entre los más destacados. Ciertamente, un "rey" (un emperador) debe complacerse en conceder favores a sus súbditos (Chrys. Or. 1.23), pero también debe hacerlo ciñéndose a lo que dicta la justicia. Nuestro objetivo en lo que sigue no es el de llevar a cabo un detallado análisis de las sutilezas legales implicadas en el proceso, sino determinar qué parámetros guiaban la actuación imperial en este sentido o, mejor dicho, debían guiar, porque la cuestión se planteaba, sobre todo, en términos éticos. Si el emperador quería separarse de la figura odiosa del tirano, sus decisiones, incluidos sus actos de liberalidad, debían someterse a los dictados de la justicia.

La generosidad romana en la concesión de su ciudadanía, contrapuesta a la "avaricia" griega, constituye un tópico bien conocido (Gauthier, 1974). Los historiadores modernos han intentado cuantificarla y los resultados de Lavan (2016) han sido tal vez los más sólidos, si bien ponen una nota de prudencia sobre el impacto numérico que tuvieron las diversas formas existentes para el acceso a la ciudadanía romana. Sin embargo, rara vez se ha planteado el problema en términos propiamente éticos, es decir, determinando en cada caso si la concesión era o no justa, lo que nos sitúa de lleno en el ámbito del beneficium, en la práctica del don y contra-don. La generosidad podía caer fácilmente en la pura arbitrariedad y ser considerada como simple largitio, es decir, en realidad, una forma de soborno (cfr. OLD s.v.). Cicerón afirma que un acto de generosidad no puede considerarse auténtica liberalitas si es injusto (Cic. Off. 1,43). Por lo tanto, el problema puede plantearse de forma sencilla: cuando se concedía la ciudadanía romana a peregrini, ¿qué papel desempeñaba la justicia? ¿Había algún criterio que permitiera separar las concesiones justas de las injustas cuando el responsable era el emperador?

\section{Ciudadanía frente a parentesco}

Podemos empezar con los impuestos, por su importancia y porque se veían directamente afectados en los casos en los que alguna persona obtenía la preciada ciudadanía romana. Plinio dedicó cuatro largos párrafos de su Panegírico (37-40) a la cuestión muy técnica de las implicaciones que tenía el cambio de ciudadanía para el impuesto de sucesiones (uicesima hereditatum). Este impuesto lo había introducido Augusto, en el año 6 d.C. con el fin de abastecer con él el aerarium militare, responsable de pagar a los soldados las debidas recompensas al licenciarse; todos los herederos estaban obligados a pagarlo, excepto los parientes más cercanos y las herencias más pobres, si bien no sabemos con seguridad ni cuál era el umbral de riqueza ni cuál el grado de parentesco requerido. Respecto de lo primero, si bien algunos autores creen que sólo estaban exentas las herencias más ricas (por encima de los cien mil sestercios), la opinión mayoritaria hoy en día se inclina por lo contrario, es decir, que la obligación afectaba a todos, salvo a los muy humildes. ${ }^{1}$ En cuanto al parentesco, probablemente solo se libraban los parientes del testador hasta el segundo grado (Günther, 2007, pp. 78-79). El problema que se planteaba, dice Plinio, derivaba del hecho de que, si uno obtenía la preciada ciudadanía romana, todos sus lazos de parentesco desaparecían ante la ley automáticamente, dejaban de ser reconocidos por ella y, por lo tanto, ya no servían para evitar el pago de la uicesima.

Esta exención de la ley se reservaba para los ciudadanos antiguos: a los nuevos, ya

1 Como dice Dion Casio $(55,25,5)$ solo se libraban de pagarlo “los parientes próximos y los pobres". Sobre esta cuestión, véase, principalmente, Gilliam (1952) quien muestra, apoyándose en P. Mich. 435 + 440, que herencias reducidas, de 1.900 dracmas $=$ sestercios, estaban sujetas al pago del impuesto. 
hubieran accedido a la ciudadanía por el derecho de Lacio o por gracia del príncipe, si no conseguían los derechos de cognación al mismo tiempo, se les consideraba como completamente extraños para sus familiares más cercanos. Así, un enorme beneficio se convertía en un gravísimo daño, y la ciudadanía romana tenía los mismos efectos que el odio, la discordia y la orfandad, pues arrebatan a las más queridas prendas, conservando sus lazos de afecto" (Plin. Pan. 37, 3-4). ${ }^{2}$

Claramente, esta no es una mera cuestión técnica que Plinio, como leal servidor del imperio, quiera poner de relieve, un aspecto puramente burocrático con el que él buscara hacer gala de su conocimiento y experiencia como antiguo praefectus del aerarium militare (94-96 d.C.) primero y del aerarium Saturni después (98-100 d.C.) (López-Cañete Quiles, 2003, p. 92). Tampoco era su única intención la de exaltar la actuación de Trajano, conforme a la ética romana de la reciprocidad. Es cierto que, como en este caso el favor imperial tuvo un alcance general, el propio emperador había renunciado a las numerosas oportunidades que habría tenido para hacerse acreedor de otros tantos favores, si hubiera optado por concesiones individuales (Plin. Pan. 39, 3; cfr. Saller 1982, p. 69 n. 169). En realidad, se trataba de una cuestión de la máxima importancia, que suponía un grave riesgo, porque este impuesto de sucesiones era uno de los dos que abastecía a la caja del ejército, el aerarium militare, encargado de librar los fondos necesarios para otorgar los debidos praemia a los veteranos al licenciarlos. Cabría incluso pensar que esta medida imperial quebrantaba la segunda regla o mandato de una justa beneficentia, según lo formuló Cicerón, es decir, que la generosidad no exceda a los medios con que contamos (Cic. Off. 1.42: ne maior benignitas sit quam facultates). Como Manolaraki (2015, p. 249) ha señalado recientemente, Plinio, de un modo sensacionalista, ha introducido en este conflicto familiar elementos y rasgos característicos del bellum ciuile: odio, discordia, orfandad. ${ }^{3}$ En suma, Plinio presentaba ante su audiencia la solución correcta para un grave problema, nacido de la necesidad de buscar un equilibrio entre las urgentes necesidades del tesoro público y las consecuencias de una ciudadanía romana en expansión. Su posición al respecto era muy clara: la obtención de la ciudadanía romana no puede llevar aparejada carga alguna, de manera que el emperador obra correctamente aprobando medidas que eliminen cualquier clase de trabas.

La decisión de Trajano a favor de los "nuevos ciudadanos" se integra en una breve lista de favores imperiales que intentaban gestionar los problemas derivados del cambio de ciudadanía. Según el derecho romano, cuando un peregrinus se convertía en romano, sus relaciones de parentesco desaparecían automáticamente, carecían de reconocimiento legal, de modo que él tampoco podría contraer un matrimonio legítimo con personas de su misma tribu o de su misma ciudad que no fuesen ciudadanas romanas. Padres e hijos, hermanos y hermanas descubrían que eran mutuamente extraños según la ley. ${ }^{4}$ Esto era algo muy injusto, afirma Plinio: era iniuria, porque obtener la ciudadanía romana debería ser un beneficio sin contrapartidas (Pan. 37,4).

2 "Haec mansuetudo legis ueteribus ciuibus seruabatur: noui, seu per Latium in ciuitatem seu beneficio principis uenissent, nisi simul cognationis iura impetrassent, alienissimi habebantur quibus coniunctissimi fuerant. Ita máximum beneficium uertebatur in grauissimam iniuriam, ciuitasque Romanam instar erat odii et discordiae et orbitatis, cum carissima pignora salua ipsorum pietate distraheret”. Las traducciones que se citan del Panegírico son de Moreno Soldevila (2010). La traducción de la última frase por Betty Radice (1969), menos fiel al original, es, sin embargo, más clara en cuanto al sentido: "It parted relatives who were dear to each other, regardless of their ties of affection".

3 Aparte de Manolaraki, no he logrado encontrar a ningún otro autor que haya tratado este tema. No hay gran cosa de interés a este respecto ni en Hammond (1938, p. 134), ni en Solimena (1905, pp. 63-65). Entre las obras generales, debemos mencionar al menos estas dos: Durry (1938) y Fedeli (1989). Los análisis de la ideología presente en el Panegyricus se han centrado de manera casi exclusiva en la dialéctica tiranía-libertad (Morford, 1992), pero hay otros aspectos del discurso que también merecen nuestra atención. No resulta convincente el intento de Molin (1989) por descubrir ideas estoicas en el Panegyricus.

4 A partir de Adriano, a los nuevos ciudadanos no se les reconocía la patria potestas sobre los hijos nacidos previamente al cambio de ciudadanía (Besson, 2017). 
Por tanto, Trajano acordó dispensar del pago de la uicesima hereditatum a los parientes cercanos de los nuevos ciudadanos, incluso aunque estos no hubieran obtenido, al mismo tiempo, los llamados "derechos de parentesco" (iura cognationis).

Con el fin de evitar que las comunidades de ciudadanos romanos acabasen convertidas en una especie de guetos, rotos todos sus lazos legales con el resto de la población, algunos emperadores, ya desde Augusto en adelante, emplearon diversos mecanismos que venían a minimizar las exigencias de una ley un tanto rígida en esto. Ese fue precisamente el origen de los fideicomisos, esto es, la necesidad de encontrar una manera para que los peregrini pudieran recibir herencias de sus parientes que eran al mismo tiempo ciudadanos romanos (Gai Inst. 2, 285). ${ }^{5}$ Adriano cerró esta vía al disponer que el fisco se apropiase de tales fideicomisos, pero la norma duró poco porque Antonino Pio restableció la situación anterior:

Este emperador dejó también las siguientes cosas dignas de recordar: todos los súbditos que eran ciudadanos romanos y cuyos hijos eran de nacionalidad griega tenían que legar su dinero, de acuerdo con una determinada ley, a los que no eran parientes, o incrementar la riqueza del emperador. Pues bien, Antonino les permitió dejar a sus hijos su herencia, prefiriendo aparecer como humanitario antes que mantener una ley ventajosa para sus finanzas. A este emperador lo llamaron Pío los romanos porque honraba mucho a la divinidad (Paus. 8, 43, 5). ${ }^{6}$

Los que habían obtenido la ciudadanía romana a través del ius Latii estaban especialmente protegidos. En los bronces flavios hallados en España se afirma con claridad que, cuando un municeps latino alcanzaba la ciudadanía romana, conservaba las relaciones previas de patria potestas, manus, mancipium, así como también sus derechos patronales sobre sus libertos (lex Irn. 22). Esencialmente, la misma información podemos leer en las Instituciones de Gayo (1,95-96). Sin embargo, este cambio de ciudadanía afectaba probablemente a otras relaciones de parentesco, como por ejemplo las que había entre hermanos, que sin duda estaban exentos de pagar la uicesima hereditatum. A mi juicio, el mismo problema es el que se quiere solventar en la llamada tabula Banasitana (168 y 177 d.C.), mediante una oscura frase saluo iure gentis. La carta de Marco Aurelio y Lucio Vero reproducida al comienzo de dicha tabla decía lo siguiente:

Hemos leído la petición de Juliano Zegrense, adjunta a tu carta y, si bien la ciudadanía romana no suele darse a estos pueblos por la indulgencia imperial, si no se alegan méritos de la mayor importancia, sin embargo, puesto que afirmas que él se cuenta entre los primeros de su pueblo y es muy leal a nosotros y obediente, y no creemos que entre los zegrenses haya muchas familias de las cuales se puedan hacer elogios comparables, y deseando que muchos otros se animen a emular a Juliano, visto el honor que dispensamos a su familia, no vacilamos en dar la ciudadanía romana, conservando los derechos de parentesco, también a Ziddina (su) esposa y asimismo a (sus) hijos Juliano, Máximo, Maximino, Diogeniano (EDCS-08800079 $=$ HDo12013 lin. 2-13). ${ }^{7}$

\footnotetext{
5 Gracias a Justiniano, Inst. 2. 25 sabemos que la institución del fideicommissum tiene su origen en la persona de L. Cornelius Lentulus, cónsul en 3 a.C. y procónsul en África, donde murió: PIR2 C 1384 y Syme (1939, p. 435, n. 9). 6 Traducción de Herrero Ingelmo (1994).

7 “ii\{i\}bellum luliani Zegrensis litteris tuis iunctum legimus et / quamquam civitas Romana non nisi maximis meritis pro/vocata in[dul]gentia principali gentilibus istis dari solita sit / tamen cum eum adfirmes et de primoribus esse popularium / suorum et nostris rebus prom(p)to obsequio fidissimum nec / multas familias arbitraremur apu $<\mathrm{d}=\mathrm{T}\rangle$ Zegrenses paria pos/s[e] de officis suis praedicare quamquam plurimos cupiamus ho/nore a nobis in istam domum conlato ad aemulationem luli/ani excitari non cunctamur et ipsi Ziddinae uxori item / liberis luliano Maximo Maximino Diogeniano civitatem / Romanam salvo iure gentis dare”. Traducción propia.
} 
La frase en sí no resulta fácil de entender porque no contamos con paralelos precisos, aunque sí alguna expresión semejante como saluo iure patroni en Gayo (Inst. 3, 72), pero aquí el problema es el término gens. En su fundamental análisis de la tabula, Sherwin-White entendía que, de esta forma, los nuevos ciudadanos romanos habrían de conservar todas las obligaciones y privilegios que ostentasen previamente en la gens Zegrensis: sacerdotia honores praemia munera. ${ }^{8}$ Sin embargo, en contra de lo que opina Sherwin-White (1973), claramente la frase en cuestión no se refiere al princeps (Iulianus), que ya era ciudadano romano, sino a su mujer y a sus cuatro hijos (lin. 10-12;19-20;35). ${ }^{9}$ En otras palabras, lo que se ventilaba aquí no eran sacerdotia honores praemia munera, sino el parentesco, es decir, que las relaciones familiares no se vieran afectadas por el cambio de ciudadanía. ${ }^{10}$ La frase saluo iure gentis, a mi entender, viene a significar esencialmente lo mismo que los cognationis iura mencionados por Plinio. ${ }^{11}$ A fortiori, la misma idea se encuentra también en la constitutio Antoniniana del 212, por la que Caracala concedió la ciudadanía romana a todos los habitantes del imperio, "preservando la ley de cada comunidad". ${ }^{12}$

\section{Trajano: ciudadanía y justicia}

En estos ultimo años, se ha sometido el libro décimo de las Cartas de Plinio el Joven a un profundo y detallado análisis por parte de los investigadores, que ha desembocado en lo que podríamos denominar un nuevo consenso: ya no podemos aceptar que se trate de una versión literal y fiel del intercambio entre el emperador y el gobernador de Bitinia, una selección al menos, de todas las que realmente se escribieron, con muy pocas alteraciones o cambios; en realidad, se afirma, el libro décimo no es sustancialmente distinto de los nueve anteriores, de modo que todo el conjunto ha de ser considerado como la versión de sí mismo que Plinio quería proyectar a los demás, es decir, un elaborado autorretrato, una hábil Selbstdarstellung o auto-representación. ${ }^{13}$ Esto no implica que las cartas sean falsas o una pura invención. Sabemos que respetan las convenciones de las cartas imperiales auténticas, conservadas en papiro, en piedra o en la compilación justinianea (Lavan, 2018). Ciertamente, Plinio sabía perfectamente cómo alterar una carta auténtica sin que pareciese falsa.

Considero que uno de los elementos principales en este autorretrato es, precisamente, la ciudadanía romana, esto es, cómo debe comportarse un buen emperador a la hora de conceder tan preciado bien a sus agradecidos súbditos a lo largo y ancho del enorme imperio. En sus cartas, en este libro décimo, Plinio solicita reiteradamente este favor

8 Sherwin-White (1973, pp. 92- 93, donde figura la cita). La traducción que ofrece Mathisen (2009) es más ambigua: "with the law of their people preserved".

9 A diferencia de lo que opina Sherwin-White (1973, p. 88, n. 9), no creo que el propio Julianus esté entre los beneficiarios. Para aceptar lo que él piensa, habría que sobrentenderlo en el texto y algo tan importante como esto cabe pensar que se proclamase de forma taxativa y sin ambigüedades en un documento público como este. En el texto los emperadores declaran que "no vacilan en dar la ciudadanía romana también a Ziddina (su) esposa y a (sus) hijos". Lógicamente, la concesión a Julianus es previa y no puede estar contenida (implícitamente) en esta última.

10 Ciertamente, Sherwin-White (1973, p. 94) reconoce que, respecto de los hijos de matrimonios mixtos, "there could be inconvenient consequences in the matter of inheritance", pero se mantiene firme en su idea de que "salvo iure gentis in an administrative context should refer primarily to public life" (1973, p. 95). Mas acertadamente, Imrie (2018, pp. 148-9) entiende que la expresión significa "preserving the local ius gentium", en el sentido de permitir a los nuevos ciudadanos seguir conviviendo con población peregrina, porque "the grant of Roman ciuitas did not exclude the recipient from access to their customary legal framework" (Imrie, 2018, p. 68).

11 Cfr. Pan. 39, 3: la decisión de Trajano permitía laceras gentilitates colligere, y aquí gentilitas es sinónimo de cognatio. Algo parecido encontramos en Pan. 37, 2: sanguine, gentilitate, sacrorum denique societate.

12 P. Giss. 40, lin. 8-9, según la interpretación de Imrie (2018, p. 148): “The underlying sentiment here, that even the mass enfranchisment of 212 honoured the existence of local custom, seems to form an easily identifiable Greek equivalent of saluo iure gentis".

13 Ver Stadter (2006); Noreña (2011a); Woolf (2015), en contra de opiniones más tradicionales como las defendidas, por ejemplo, por Coleman (2012). 
imperial para algún conocido o para recompensar a alguno de los suyos, algo que reiteradamente Trajano le concede al punto. La lista es bastante larga: Harpócrate, el médico de Plinio (10, 5-7; 10); la hija (no ciudadana) de un centurión romano (10, 1067); dos latinos junianos manumitidos por Antonia Maximila (10, 5); tres junianos que habían sido "legados" a Plinio por su amigo Valerio Paulino (10, 104-5); tres junianos más $(10,11)$; finalmente, una familia entera -marido, esposa y dos hijos-emparentados con el médico que había curado en una ocasión a Plinio. La suma total asciende a 14 nuevos ciudadanos, 8 de ellos latinos junianos (un número desde luego sorprendentemente elevado) y 6 peregrini. Trajano parece conceder todas las solicitudes e incluso se muestra dispuesto a otorgar el mismo favor a otros si Plinio tiene a bien solicitarlo (10, 105). Es verdad que, en uno de estos casos $(10,11)$, no sabemos cuál fue la respuesta (si es que hubo alguna), pero podemos dar por hecho que todas las solicitudes fueron atendidas. ${ }^{14}$ No siempre Plinio da algún detalle sobre los beneficiarios o sus circunstancias personales, la mayor parte de los casos formula su petición directamente, sin circunloquios. ${ }^{15}$ Con todo, en algún caso, tiene que tocar algunos aspectos técnicos, de modo que el problema reaparece en varias cartas, lo cual es muy inusual en este libro décimo, en el que rara vez se repiten los mismos temas, lo cual hace que la cuestión de la ciudadanía cobre mayor relevancia. Podemos concluir, pues, que la imagen de un emperador dispuesto a conceder la ciudadanía romana a sus fieles súbditos, si algún buen amigo intercede por ellos, es un elemento central en la imagen que Plinio quiere proyectar de sí mismo y de sus vínculos con el príncipe. Este mismo espíritu es el que subyace a las concesiones de la ciudadanía romana que Trajano ofreció como una vía abierta a los latinos junianos que mantuviesen en funcionamiento una tahona en Roma durante tres años (Gai Inst. 1, 34). Esta generosidad contrasta abiertamente con la renuencia de Trajano a la hora de otorgar el ius trium liberorum: "Sabes perfectamente cuán limitadamente concedo estos beneficios, mi queridísimo Segundo": tal es el inicio de la respuesta del emperador, que, sin embargo, concede el privilegio que se le solicita, en favor de Suetonio Tranquilo, el biógrafo de los Césares (Ep. 10, 95).

Teniendo en cuenta todas estas menciones que encontramos en las Cartas, no sorprende ver que también en el Panegírico se exalta la generosidad de Trajano, pero aquí la atención se centra en un aspecto distinto. Plinio subraya el creciente número de ciudadanos, tanto antiguos como nuevos. El día en que Trajano entró en Roma como nuevo emperador, el año 99 d.C. "incluso las mujeres sintieron más que nunca el gozo de su fertilidad al ver para qué príncipe habían parido ciudadanos, para qué general soldados" (Pan. 22, 3). Plinio se detiene en hacer algún comentario sobre el nuevo Circo Máximo, pues se le han añadido cinco mil asientos a los que ya tenía $(P a n .51,5)$. Tanta generosidad encontró apropiada conmemoración en un pedestal en el que las treinta y cinco tribus ensalzaban la liberalitas optimi Principis, y también en un sestercio, acuñado en 104-111, con una vista general del Circo Máximo en el anverso. ${ }^{16}$ Plinio insiste varias veces en esta idea:

Con todo, el hecho fundamental es que eres de tal manera que bajo tu mandato es deseable y ventajoso criar hijos. Ningún padre teme ya por su hijo más allá de los lances de la fragilidad humana y no se cuenta entre las enfermedades incurables la ira del príncipe. Es un gran estímulo para la crianza tener niños con la esperanza de que van a recibir alimentos y congiarios, pero lo es mayor tenerlos con la esperanza

14 Millar (200o, p. 375) sostiene que todas estas peticiones fueron rechazadas. En buena medida, todo depende de la cronología de las cartas porque Plinio fue designado augur en 103, de manera que si Ep. 10, 7 (en la que solicita el augurado o el septemvirado) corresponde al año 102, entonces no habría tanta distancia entre la solicitud y la respuesta como para pensar que primero fue rechazada y luego concedida.

15 Sherwin-White (1985, p. 567) advierte su brusquedad en Plin. Ep. 10, 5, 2.

16 CIL VI, 955 = ILS 286, del año 103, dedicada al emperador por las treinta y cinco tribus: "quod liberalitate optimi principis commoda earum etiam locorum adiectione ampliata sint" (Mattingly, BMC III, 180 n.853 = P. Pavón, en González-Saquete, 2003: 479 nº 8). Sobre liberalitas en la propaganda de Trajano, véase Cotton (1984). 
de la libertad y la seguridad (Pan. 27, 1).

Se trata de una frase importante porque de ella cabe inferir que el propósito de frumentationes y congiaria era precisamente el de incrementar la tasa de natalidad. Como es sabido, se han propuesto muchas explicaciones diferentes para los alimenta (y no es este el lugar adecuado para pasar revista de todas), hasta el punto que algún autor se muestra radicalmente escéptico y considera que no podemos de ninguna manera conocer las intenciones que Trajano tenía cuando puso en marcha el programa (Seelentag, 2008, p. 229). Con todo, la frase de Plinio que acabamos de citar abre una vía para conocer cuáles eran en realidad. En aquellos momentos, es decir, en septiembre del año 100, se sabía que los alimenta iban a empezar en apenas uno o dos meses -sin tener en cuenta ahora el hecho de que el Panegírico fue reescrito después de pronunciado-, de manera que cabe interpretar lo que dijo Plinio como una síntesis de los objetivos que se perseguían y que no eran otros, como hemos visto, que aumentar el número de nacimientos. Esta era una preocupación importante para el nuevo emperador. Así, de nuevo, en el Panegírico: "Para criar a sus hijos, se anima a los ricos con grandes premios y similares castigos, el único recurso para que los pobres saquen adelante a los suyos es un buen príncipe" (Plin. Pan. 26, 5). Se trata de una frase un tanto extraña, porque, como acabamos de ver, los pobres tienen otros estímulos, como alimenta y congiaria, de forma que el hecho de que no los mencione aquí puede causar extrañeza y servir de apoyo para quienes opinan que los destinatarios de los alimenta no eran los pobres de solemnidad (Woolf, 1990; en contra Lo Cascio, 2000). Con todo, debemos tener en cuenta que Plinio busca aquí marcar el contraste entre el buen emperador y el malo, lo cual constituye, por decirlo así, la columna vertebral del Panegírico. Numerosos pasajes giran en torno a esta idea y la conclusión es evidente: bajo un buen emperador, la natalidad crece, en parte debido a los alimenta, pero sobre todo porque el pueblo vive seguro, sin sentir miedo. La conexión entre el número de nacimientos y el buen emperador, tan importante en Plinio, es menos evidente de lo que parece. Plutarco, por ejemplo, considera que la abundancia de hombres es algo que depende enteramente de los dioses (Praec. Reip. ger. $824 \mathrm{C}-\mathrm{D}$ ), mientras que, para Plinio, la fecundidad femenina es la señal distintiva del buen gobernante. Podemos avanzar un poco más en esta misma línea recordando las conclusiones que hemos obtenido del libro décimo de las Cartas: cabe distinguir el buen emperador del malo en que, bajo el primero, el cuerpo político crece. Esta es la razón que subyace a la generosidad de Trajano tal como Plinio quiere presentárnosla.

El contraste entre el tirano y el buen emperador es el tema principal en torno al que gira todo el pensamiento político durante el Principado. Este contraste puede expresarse como la oposición entre "miedo" y "seguridad". El primero provoca que descienda el número de ciudadanos, porque nadie está a salvo ni cabe confiar en un futuro mejor, mientras que el segundo concepto, es decir, securitas, es el fundamento de la aeternitas, con más y más ciudadanos viviendo en una confortable paz. El principal mensaje del Panegyricus es que ahora, bajo Trajano, los ciudadanos disfrutan de la libertas porque ahora viven seguros, sin miedo. ${ }^{17}$ Una generosa política en cuanto a la ciudadanía es, en consecuencia, uno de los rasgos que caracteriza al buen emperador. Así lo reconoce y subraya Elio Arístides, en tiempos de Adriano: "Vosotros os habéis convertido en los geógrafos comunes para todos al haber abierto todas las puertas de la ecúmene (...), al haber establecido normas matrimoniales comunes y al haber organizado toda la ecúmene como una sola casa". ${ }^{18}$

17 Connolly, 2009, p. 262. Evidentemente, hay una cierta paradoja aquí, como lo ha advertido Kloft (1970, p. 93), porque securitas depende de liberalitas y esta última, a su vez, depende de la libre voluntad del emperador, que puede cambiar en un momento determinado. Sólo gracias a un perpetuum congiarium puede alcanzarse la anhelada securitas.

18 Elio Arístides, A Roma, 102. Traducción de Cortés Copete (1997). 
Ahora conviene que centremos nuestra atención en el reverso del cuadro. Los ataques contra dinastas o contra emperadores por su excesiva generosidad a la hora de conceder la ciudadanía romana tienen una larga historia, que se remonta, por lo menos, a los injuriosos cánticos que circulaban por Roma sobre los galos a los que César había concedido la ciudadanía y un asiento en el Senado (Suet. Iul, 80, 2; cfr. 76, 3). Unos años más tarde, Cicerón censuraba con gran irritación el hecho de que Marco Antonio hubiese concedido la ciudadanía a los sicilianos (Att.14, 12, 1 = SB 366; la ley fue posteriormente abolida). La reticencia de Augusto a este respecto era bien conocida. Según Suetonio:

\begin{abstract}
Así, en una ocasión en que Tiberio le pidió la ciudadanía para un cliente suyo que era griego le contestó "que solo se la concedería en el caso de que a viva voz consiguiera convencerle de que eran muy justificadas las razones en que apoyaba su petición". En otra ocasión en que Livia le pedía también la ciudadanía para un contribuyente galo, se la negó y como compensación le ofreció la exención de tributo, afirmando "que le era más fácil resignarse a mermar un poco el fisco que a profanar la dignidad de la ciudadanía romana" (Aug. 40, 3).19
\end{abstract}

Séneca se burla del emperador Claudio por haber acordado que todos los griegos, galos, hispanos y britanos vistan la toga (Apocol. 3). En un tono más serio, se pregunta qué ocurriría si un príncipe concediese, mediante decreto, la ciudadanía a los galos (Sen. Ben. 6.19.2). En su opinión, este es un favor concedido a un colectivo, que no genera el mismo tipo de obligaciones personales como sí lo hacen los favores particulares (Griffin, 2013, p. 219). Esta breve recopilación de opiniones críticas culmina con la constitutio Antoniniana (212 d.C.), mediante la cual Caracala convirtió a todos sus súbditos en ciudadanos romanos, algo por lo que recibió la severa condena de Dion Casio: la medida habría obedecido tan sólo a la necesidad que tenía Caracala de incrementar la recaudación de algunos impuestos, los que pagaban los ciudadanos romanos (D.C. 77, 9, 5). Lo animaba la codicia, no la búsqueda del bien común; no estaba dando un beneficium, como había hecho Trajano, sino que lo estaba vendiendo. ${ }^{20}$

Párrafo aparte merecen las críticas de Tácito, en tanto que contemporáneo de Plinio. Con un lenguaje duro, Tácito asocia estas concesiones con emperadores irresponsables, que se encuentran en situaciones límite y han perdido casi toda esperanza de sobrevivir; Otón otorgó la ciudadanía romana a la tribu gala de los Lingones: esto fue una largitio, un término que implica una condena moral y suele asociarse con la rivalidad y la lucha política (Tac. Hist. 1, 78, 1; Phang, 2008, p. 181). Después de que sus tropas fuesen derrotadas en Bedriacum, Vitelio, negándose a afrontar la realidad del avance inminente del ejército flavio, se dio al lujo y al despilfarro, condonándoles a algunos las deudas atrasadas, perdonándoles a otros el pago de los impuestos y dilapidando (de nuevo dilargiri) el Latium, dándoselo a extranjeros (externis), en suma, concluye Tácito, desmantelando el imperio (Tac. Hist. 3, 55, 2). Tanto Otón como Vitelio, en el retrato que de ellos nos ha dejado Tácito, se muestran demasiado dadivosos; su generosidad, en realidad, está corrompida, es simple prodigalidad (Phang, 2008, p. 186). Tal vez Plinio el Viejo se hiciese eco precisamente de estos episodios relacionados con Otón y Vitelio, cuando escribió que el ius Latii se había visto "sacudido" o, en otra traducción posible, "arrojado", debido a los disturbios de la República, disturbios que tenemos que entender referidos a

19 Traducción de Bassols de Climent (2007).

20 A pesar de la hostilidad evidente que siente Dion Casio por Caracala, no podemos descartar que ese fuese uno de los objetivos principales de la medida, es decir, incrementar la liquidez para poder pagar a los legionarios. Véase el detallado análisis de Imrie (2018), quien infravalora los motivos religiosos de la concesión, puestos de relieve por De Blois (2014). 
los ocasionados por la guerra civil librada tras la muerte de Nerón. ${ }^{21}$ Este ius Latii fue un regalo, un munus, que Vespasiano concedió a "toda Hispania" y también a Icosium (actual Argel), en África. ${ }^{22}$

A diferencia de estos malos precedentes, Trajano adoptó medidas adecuadas, las que corresponden a un buen patrono, no las propias de un mercader. "Ofreciste el congiario alegrándote con los que se alegraban, sintiéndote seguro con los que se sentían seguros. Y lo que los príncipes anteriores arrojaban al pueblo enfurecido para mitigar el odio que sentían hacia él, tú se lo diste al pueblo con la misma inocencia con la que él lo recibió" (Plin. Pan. 28, 3). Esa es la clave, la inocencia, es decir, un favor que no nace de la culpa. Un beneficium debe ser siempre un acto libre, no el cumplimiento de una obligación ni el producto de una situación desesperada. Por esa razón, precisamente, todas las concesiones del emperador, incluso los actos administrativos más banales, pueden ser concebidos como beneficia, en la medida en que él, al situarse por encima de la ley (princeps a legibus solutus), siempre actúa y se comporta con entera libertad. ${ }^{23}$

\section{Justicia y generosidad}

Según Cicerón, la justicia y la generosidad (beneficentia, benignitas, liberalitas), aunque muy próximas la una de la otra, son virtudes distintas, si bien no llega a explicar exactamente por qué (Cic. Off. 1, 20). Teniendo presente su preocupación casi obsesiva por la protección de la propiedad privada contra cualquier ataque, es tentador expresar esa diferencia del siguiente modo: la justicia implica la defensa a ultranza de la propiedad privada, mientras que la generosidad nos obliga a compartir nuestro patrimonio con amigos y conciudadanos. Si esto es lo que las distingue, lo que las asemeja, lo que tienen en común, según lo ha señalado Atkins (1990, p. 266), es que, para Cicerón, ambas colaboran desempeñando funciones complementarias, en la construcción de la societas. ${ }^{24}$ Esto significa que la generosidad es un elemento esencial para que exista una comunidad política. Luego, Cicerón rechaza la idea, que considera muy extendida, según la cual debe ayudarse primero al hombre rico e influyente, antes que al pobre, pero más virtuoso $(O f f .2,69)$. Concluye que la generosidad debe graduarse en función de la valía (dignitas) de los beneficiarios, "porque ese es el fundamento de la justicia, y a ella deben referirse todas las cosas" (Cic. Off. 1, 42). ${ }^{25}$ Esto es especialmente importante cuando el beneficiario solicita la ciudadanía romana, porque esta es "una recompensa de la virtud" (praemium uirtutis, Balb.47). Encontramos la misma idea al comienzo de la tabula Banasitana, en el párrafo citado más arriba: es necesario hacer "grandes méritos" y demostrar una lealtad extraordinaria a Roma y al emperador. ${ }^{26}$

21 "Uniuersae Hispaniae Vespasianus imperator Augustus iactatum procellis rei publicae Latium tribuit" (Plin. NH 3, 30). Para la lectura "iactatum" (scil. Latium), presente en la mayor parte de los manuscritos y generalmente acogida por los editores modernos -por encima de iactatus (scil. Vespasianus) o incluso iactatae (scil. Hispaniae) -, véase Zecchini (1990), si bien no estoy de acuerdo con su interpretación que entiende aquí el Latium como referido tanto al ius Latii como a la región geográfica de Lacio.

22 "Eiusdem [scil. Claudii] iussu deductis ueteranis Oppidum Nouum et Latio dato Tipasa, itemque a Vespasiano Imperatore eodem munere donatum Icosium” (Plin. $\mathrm{NH}_{5}, 20$ ).

23 Veyne, 1976, p. 624. El requisito de que el beneficium ha de ser un acto libre, no una obligación legal, se aprecia de modo especial en el beneficium manumissionis (López Barja, 1993 y Querzoli, 2009).

24 También para Séneca “l'échange de bienfaits est fondateur de l’ordre social” (Gonzales, 2016, p. 129).

25 Es posible que, como opina Dyck (1996, p. 157), Panecio fuese en este punto la fuente que usó Cicerón, pero esto no es relevante para nosotros ahora.

26 "Quamquam ciuitas Romana non nisi maximis meritis prouocata indulgentia principali gentilibus istis dari solita sit, tamen cum eum adfirmes et de primoribus esse popularium suorum et nostris rebus prompto obsequio fidissimum..." (I, 3-6). En la epistula por la que le concede la ciudadanía romana a Seleuco de Rodas, Octaviano destaca los servicios que le ha prestado a él personalmente, no a Roma (FIRA I, 55, 2, II.12-18). 
Nada semejante encontramos en el intercambio epistolar entre Plinio y Trajano, pues el primero en ningún momento se detiene a especificar los méritos de las personas para las que solicita la ciudadanía romana. Debemos asumir que, en estos casos, el emperador confía en el buen juicio de su leal gobernador de Bitinia. Seguramente, el documento oficial en el que constase la concesión de la ciudadanía incluyese toda esta retórica sobre merecimientos, servicios prestados y lealtades, pero también cabe pensar que todas estas nobles palabras encerraban un significado real. Los favores dispensados por Trajano se ajustaban a lo que dicta la justicia, no porque los beneficiarios los mereciesen, sino porque un gran número de ciudadanos era algo bueno para Roma. Esta política natalista explica la relevancia que la ciudadanía tiene en las cartas de Plinio y en el Panegírico, y también nos ayuda a entender por qué Plinio se entretuvo en un asunto tan árido y técnico como la condonación de la uicesima hereditatum a los nuevos ciudadanos. Todas estas muestras de la magnanimidad imperial eran buenas y justas, pese a que dañaban el erario, porque no buscaban simplemente reforzar la posición de Trajano sino el bien común.

De hecho, esta política servía para situar a Roma y su Imperio sobre "el más sólido de los fundamentos", una frase que Plinio emplea en dos ocasiones. Trajano autorizó la inclusión de cinco mil niños de nacimiento libre en la lista de beneficiarios de los repartos mensuales de grano a la plebe de Roma: "Ellos, apoyo en los momentos de guerra y ornato en los de paz... con ellos se volverán a llenar los campamentos, con ellos las tribus". ${ }^{27}$ Encontramos este doblete subsidium belli, ornamentum pacis -varias veces mencionado en Cicerón y en Livio $(26,21,1)$ - referido a los recursos y equipos necesarios para la guerra o vivir confortablemente en tiempo de paz. ${ }^{28}$ Hay una sola excepción, cuando Cicerón define, con un sentido más abstracto, al ordo publicanorum como ornamentum ciuitatis (Cic. Planc. 23). Plinio emplea esta expresión también en una de sus cartas. En un momento dado, solicita a su amigo, Calestrio Tirón, procónsul de la Bética, que se desvíe en su camino a esa provincia para visitar a Calpurnio Fabato (abuelo de la mujer de Plinio), con el fin de que este último pudiera manumitir uindicta (es decir, en presencia del procónsul) a unos esclavos que había liberado recientemente de un modo informal, es decir, inter amicos (Ep. 7, 16; cfr. López Barja, 2008, 17). Una vez concluido el proceso, Plinio escribe de nuevo a Fabato para felicitarle por lo que ha hecho, porque la manumisión de esclavos es algo bueno y positivo: "Siempre he deseado, en efecto, que nuestra ciudad nativa aumente en todos los aspectos, especialmente en el número de ciudadanos; pues éste es el más sólido fundamento de las ciudades". ${ }^{29}$ Recapitulando: subsidium bellorum y ornamentum pacis eran, en el Panegírico los cinco mil niños de nacimiento libre admitidos en las frumentationes; en las Cartas de Plinio, el ornamentum oppidis (esto es, Comum) eran los libertos. No menciona en este caso su posible contribución al esfuerzo militar (subsidium bellorum) tal vez porque, a diferencia de los niños ingenui, los libertos no podían, por ley, servir en las legiones. En otras palabras, la abundancia de ciudadanos, tanto "antiguos" como "nuevos" le parecía a Plinio algo intrínsecamente tan bueno y positivo como la tierra pública o el dinero público le habían parecido a Cicerón. La manumisión se concibe, por tanto, como una forma de evergetismo, de favorecer e impulsar a las ciudades y a la propia Roma. Plinio, como probablemente también otros aristócratas, no hacía otra cosa que seguir el ejemplo marcado por Trajano. ${ }^{30}$

27 Plin. Pan. 28.5: "subsidium bellorum, ornamentum pacis... ex his castra ex his tribus replebuntur".

28 Cic. leg. Agr. 1,3: "tu ullum uectigal attingas, tu populo Romano subsidia belli, tu ornamenta pacis eripias"; cfr. 2, 80; Cic. 2 Verr. 5, 124; Cic. Pro Murena 30; Cic. Manil. 6; Cic. Orat. 2, 171.

29 "Cupio enim patriam nostram omnibus quidem rebus augeri, maxime tamen ciuium numero: id enim oppidis firmissimum ornamentum” (Plin. Ep. 7,32,1). Traducción de González Fernández (2005).

30 Sobre la convergencia, en el siglo II d.C. entre los emperadores y los aristócratas locales como modelo de evergetismo cívico, véase Noreña (2011b, p. 292). 
Estos ideales también encontraron su sitio en la propaganda oficial. Los congiaria se celebraban en las acuñaciones. ${ }^{31}$ Los relieves del arco de Benevento, erigido en 114 d.C., como ha mostrado Torelli (1997, pp. 167-179), venían a exaltar la institutio alimentaria, y presentan muchas concomitancias con las ideas vertidas por Plinio en el Panegírico. Es posible que tengamos incluso un elogio explícito de esta política natalista en una inscripción de Roma, datada entre el 10 de diciembre del 107 y el 9 de diciembre del 109, y tal vez originalmente emplazada en el Aventino. La inscripción es una dedicatoria a Trajano, propagatori orbis terrarum, locupletatori ciuium, realizada por los cultores Larum et imaginum domus Augustae. Locupletator siempre va acompañado de un genitivo, habitualmente, un genitivo objetivo. Trajano enriqueció a los ciudadanos de muchas formas, incluyendo tal vez el hecho de que el propio número de ciudadanos se incrementó igualmente (si entendemos que es un genitivo subjetivo). ${ }^{32}$ Otra dedicatoria a Trajano también procedente de Roma es más explícita a este respecto, pero por desgracia está dañada y la parte de ella que nos interesa no es más que una reconstrucción hipotética. ${ }^{33}$

Emma Dench (2005, pp. 142-3) postula un contraste entre la generosidad romana (respecto de la ciudadanía) durante la Republica y una cierta "reluctancia" a este respecto en el Alto Imperio. Sin embargo, tal reluctancia resulta ciertamente difícil de ver. La concesión del ius Latii por Vespasiano tuvo como consecuencia la creación, cada año, de nuevos ciudadanos en Hispania, de forma sostenida y el Panegírico de Plinio muestra que Trajano tomó iniciativas legislativas con el fin de eliminar las molestas consecuencias de un cambio de ciudadanía. La introducción del Latium maius por Adriano tuvo que acelerar este proceso aún más, si bien la abolición, por Antonino Pío, de las concesiones a los hijos de los auxiliares al licenciarse vino a contrarrestar un tanto el incremento. A mi juicio, probablemente el freno más importante a la creación de nuevos ciudadanos tuvo lugar al principio, con las leyes augusteas sobre la manumisión (leges Iunia y Aelia Sentia), que redujeron de modo drástico la transformación de esclavos en ciudadanos romanos. En opinión de Oliver (1953, p. 947), en la época de Elio Arístides, la mayoría de las familias más importantes de las poleis griegas habían ya obtenido la ciudadanía romana. Desde una perspectiva menos impresionista, Myles Lavan (2016, p. 16) ha concluido recientemente que la proporción de ciudadanos romanos (respecto del total de habitantes del imperio) pasó del $6 \%$ en el año 14 d.C. al $22 \%$ en el año 212. Es decir, que el incremento superó el $300 \%$, en la que es la estimación más baja de las realizadas hasta ahora. Un buen emperador, como también un buen ciudadano (Calpurnio Fabato, Plinio), aporta nuevos ciudadanos, que antes eran provinciales o esclavos. Esto coloca a las ciudades de Italia y el imperio sobre "el más sólido de los fundamentos".

31 Véase, por ejemplo, Mattingly, BMC III, p. 162 n. 769 = P. Pavón, en González-Saquete (2003, p. 482 n. 15).

$32 \mathrm{CIL} \mathrm{VI} 958=40500=\mathrm{HDo} 25628$. La palabra locupletator no aparece en ningún texto literario antes del siglo IV, cuando la emplea Eutropio $(10,15,2)$ para indicar que Constancio II era familiarium etiam locupletator. Sólo aparece en otra ocasión más, en un mármol de Gabii, dedicado a Adriano y su esposa, "los enriquecedores del municipium" $($ CIL XIV 2799 = ILS $321=$ AE 2000, 251 = EDR154857); cfr. Boatwright (1989) y Coarelli (2000). De acuerdo con el Th.L.L. VII, 2 p. 1573, 70-76: locupletator = diuitiarum largitor. También lo encontramos en una moneda: Mattingly-Sydenham (1926, p. 415, n. 585), Hadr. locupletatori orbis terrarum. Estos substantivos en -tor son, en general, tardíos, pero el verbo no es en absoluto infrecuente como es bien sabido: (Romulus) et cum ipse nihil ex praeda domum suum reportaret, locupletare ciues non destitit" (Cic. De re publ. 2, 15).

33 CIL VI 40497 = 31298, lin. 5-6: “benefici]o eius ciu[ium numero ---? /augendo?]”. 


\section{Dibliografía}

"Atkins, E. M. (1990). Domina et Regina Virtutum: Justice and Societas in De Officiis. Phronesis, 35, 258-289.

» Bassols de Climent, M. (Trad.). (2007). Suetonio. Vida de los doce césares. Madrid: CSIC.

» Besson, A. (2017). Fifty Years before the Antonine Constitution: Access to Roman Citizenship and Exclusive Rights. En L. Cecchet y A. Busetto (Eds.), Citizens in the GraecoRoman World: Aspects of Citizenship from the Archaic Period to AD 212 (199-220). LeidenBoston: Brill.

» Boatwright, M. T. (1989). Hadrian and Italian Cities. Chiron, 19, 235-271.

"Coarelli, F. (2000). Alcuni ipotesi sull'evergetismo imperiale in Italia. En M. CébeillacGervasoni (Ed.), Les élites municipales de l'Italie péninsulaire de la mort de César à la mort de Domitien entre continuité et rupture (137-148). Roma: École Française de Rome.

" Coleman, K. M. (2012). Bureaucratic Language in the Correspondence between Pliny and Trajan. TAPhA, 142, 189-238.

»Connolly, J. (2009). Fear and Freedom: A New Interpretation of Pliny's Panegyricus. En G. Urso (Ed.), Ordine e Sovversione nel Mondo Greco e Romano. Atti Del Convegno Internazional (259-278). Pisa: Fondazione Canussio.

»Cortés Copete, J. M. (Trad.). (1997). Elio Arístides. Discursos XVII-XXXV. Madrid: Gredos.

" Cotton, H. (1984). The Concept of Indulgentia under Trajan. Chiron, 14, 245-266.

"De Blois, L. (2014). The Constitutio Antoniniana (AD 212): Taxes or Religion?. Mnemosyne, 67, 1014-1021.

»Dench, E. (2005). Romulus' Asylum. Roman Identities from the Age of Alexander to the Age of Hadrian. Oxford: Oxford University Press.

»Durry, M. (1938). Pline le Jeune. Panégyrique de Trajan. París: Les Belles Lettres.

"Dyck, A. R. (1996). A Commentary on Cicero: De Officis. Ann Arbor: University of Michigan Press.

》Fedeli, P. (1989). II Panegirico di Plinio nella critica moderna. ANRW II.33.1, 387-514.

" Gauthier, Ph. (1974). 'Generosité' romaine et 'avarice' grecque: sur l'octroi du droit de cité". En Mélanges d'histoire romaine offerts à William Seston (207-215). París: E. de Boccard.

" Gilliam, J. F. (1952). The Minimum Subject to the Vicesima Hereditatium. AJP, 73, 397-405.

"Gonzales, A. (2016). Beneficium [sibi] dare socialis res est. Les exclus peuvent-ils faire le bien?. Mediterraneo Antico, 19, 125-144.

» González, J. y Saquete, J. C. (Eds.). (2003). Marco Ulpio Trajano, emperador de Roma. Documentos y fuentes para el estudio de su reinado. Sevilla: Junta de Andalucía.

» González Fernández, J. (Trad.). (2005). Cayo Plinio Cecilio Secundo. Cartas. Madrid: Gredos.

» Griffin, M. (2013). Seneca on Society: A Guide to De Beneficiis. Oxford: Oxford University Press.

" Günther, S. (2007). Das Regelungswerk der lex vicesima hereditatium und seine Modifikationen in späterer Zeit. En S. Günther, K. Ruffing y O. Stoll (Eds.), Pragmata: Beiträge 
zur Wirtschaftsgeschichte der Antike im Gedenken an Harald Winkel (74-88). Wiesbaden: Harrassowitz.

» Hammond, M. (1938). Pliny the Younger's Views on Government. HSCPh, 49, 115-140.

» Herrero Ingelmo (Trad.). (1994). Pausanias. Descripción de Grecia. Madrid: Gredos.

»Imrie, A. (2018). The Antonine Constitution: An Edict for the Caracallan Empire. Leiden: Brill.

» Kloft, H. (1970). Liberalitas Principis. Herkunft und Bedeutung. Colonia: Böhlau.

»Lavan. M. (2016). The Spread of Roman Citizenship, 14-212 CE: Quantification in the Face of High Uncertainty. PEP, 230, 3-46.

» Lavan, M. (2018). Pliny Epistles 10 and Imperial Correspondence. En A. König y C. Whitton (Eds.), Roman Literature under Nerva, Trajan and Hadrian: Literary Interactions, AD 96-138 (280-301). Cambridge: Cambridge University Press.

» Lo Cascio, E. (200o). Alimenta Italiae. En J. González (Ed.), Trajano, Emperador de Roma. Actas del Congreso Internacional, Sevilla 14-17 septiembre 1998 (287-312). Roma: L’Erma di Bretschneider.

» López Barja, P. (1993). El beneficium manumissionis, la obligación de manumitir y la virtud estoica. DHA, 19, 47-64.

» López Barja, P. (2008). Historia de la manumisión en Roma. Madrid: Universidad Complutense de Madrid.

» López-Cañete Quiles, D. (2003). Plinio. El Panegírico de Trajano. En J. González y J. C. Saquete (Eds.), Marco Ulpio Trajano, emperador de Roma. Documentos y fuentes para el estudio de su reinado (89-230). Sevilla: Junta de Andalucía.

» Manolakari, E. (2015). Death and Taxes: The uicesima hereditatum in Pliny's Panegyricus. En O. Devillers (Ed.), Autour de Pline le Jeune. En hommage à Nicole Méthy (244-258). Burdeos: Ausonius Éditions.

» Mathisen, R. (2009). Provinciales, Gentiles and Marriages between Romans and Barbarians in the Late Roman Empire. JRS, 99, 140-155.

» Mattingly, H. y Sydenham, E. A. (1926). The Roman Imperial Coinage, II: Vespasian to Hadrian, Londres: Spink and Son.

» Millar, F. (2000). Trajan: Government by Correspondence. En J. González (Ed.), Trajano, Emperador de Roma. Actas del Congreso Internacional, Sevilla 14-17 septiembre 1998 (363388). Roma: L'Erma di Bretschneider.

» Molin, M. (1989). Le Panégyrique de Trajan: éloquence d'apparat ou programme politique néo-stoïcien?. Latomus, 48, 785-797.

» Morford, M. P. O. (1992). lubes Esse Liberos: Pliny's Panegyricus and Liberty. AJP, 113, 575593.

» Moreno Soldevila, R. (Ed. y Trad.). (2010). Plinio el Joven. Panegírico de Trajano, Madrid: CSIC.

» Noreña, C. F. (2011a). Self-Fashioning in the Panegyricus. En P. Roche (Ed.), Pliny's Praise: The "Panegyricus" in the Roman World (29-44). Cambridge: Cambridge University Press.

» Noreña, C. F. (2011b). Imperial Ideals in the Roman West. Cambridge: Cambridge University Press.

» Oliver, J. H. (1953). The Ruling Power: A Study of the Roman Empire in the Second Century after Christ through the Roman Oration of Aelius Aristides. TAPhS, 43, 872-1003. 
"Phang, S. E. (2008). Roman Military Service: Ideologies of discipline in the Late Republic and Early Principate. Cambridge: Cambridge University Press.

»Querzoli, S. (2009). II beneficium della manumissio nel pensiero di Ulpio Marcello. Ostraka, 18, 203-220.

» Radice, B. (Ed. y Trad.). (1969). Letters, and Panegyricus. Cambridge: Harvard University Press.

» Saller, R. (1982). Personal Patronage under the Early Empire. Cambridge: Cambridge University Press.

» Seelentag, G. (2008). Der Kaiser als Fürsorger - die italische Alimentarinstitution. Historia, 57, 208-241.

»Sherwin-White, A. N. (1973). The Tabula of Banasa and the Constitutio Antoniniana. JRS, $63,88-98$.

» Sherwin-White, A.N. (1985). The Letters of Pliny: A Historical and Social Commentary. Oxford: Clarendon Press.

»Solimena, C. (1905). Plinio il giovine e il diritto pubblico di Roma. Nápoles: Pierro.

»Stadter, P. A. (2006). Pliny and the Ideology of Empire: The Correspondence with Trajan. Prometheus, 32, 61-76.

» Syme, R. (1939). The Roman Revolution. Oxford: Clarendon Press.

» Torelli, M. (1997). Ex his castra, ex his tribus replebuntur: The Marble Panegyric on the Arch of Trajan at Beneventum. Studies in the History of Art, 49, 144-177.

» Veyne, P. (1976). Le pain et le cirque. París: Le Seuil.

»Woolf, G. (1990). Food, Poverty and Patronage: The Significance of the Epigraphy of the Roman Alimentary Schemes in Early Imperial Italy. PBSR, 45, 197-228.

»Woolf, G. (2015). “Pliny/Trajan and the Poetics of Empire”. CPh, 110, 132-151.

»Zecchini, G. (1990). Plinio il Vecchio e la lex lulia municipalis. ZPE, 84, 139-146. 